\title{
CONDIÇÕES GEOMÉTRICAS DE VIAS URBANAS PARA O ACESSO DO SERVIÇO PÚBLICO DE EMERGÊNCIA EM SITUAÇÕES DE INCÊNDIO
}

\author{
Ivan Ricardo Fernandes ${ }^{1}$
}

\section{RESUMO}

O fogo e os grandes incêndios sempre estiveram presentes no contexto social, muitas vezes com perdas de vidas humanas e bens materiais. As normativas do Corpo de Bombeiros procuram sanar este problema, no entanto as condições de acessibilidade e mobilidade de vias urbanas tem dificultado a prestação do serviço público de emergência em situação de incêndio. Contribui ainda com este cenário, o fragmentado processo de urbanização brasileira, onde famílias passaram a ocupar áreas impróprias à moradia humana. Os conceitos de mobilidade urbana, em muito são tratados no sentido de restringir a circulação de automóveis e incentivar a locomoção de pessoas, sem atentar a temática do acesso de viaturas de emergência. $\mathrm{O}$ objetivo desta pesquisa foi verificar as condições geométricas de vias urbanas em três municípios do entorno de Curitiba, as quais apresentaram irregularidades na largura, no raio mínimo de giro e no gabarito vertical mínimo de suas vias. Para esta verificação foi necessário generalizar os conceitos das vias urbanas dos municípios, em função do Código de Trânsito Brasileiro (BRASIL, 1997), bem como das viaturas do Corpo de Bombeiros em função do Manual de Projeto Geométrico de Travessias Urbanas (BRASIL, 2010).

Palavras-chave: Urbanização; Bombeiros; Mobilidade.

\footnotetext{
${ }^{1}$ Bombeiro Militar, Eng. Civil, Mestre; Corpo de Bombeiros do Paraná; Curitiba, Paraná; ivan.r@pucpr.br
} 


\title{
GEOMETRIC CONDITIONS OF URBAN WAYS TO ACCESS THE PUBLIC EMERGENCY SERVICE IN FIRE SITUATIONS
}

\begin{abstract}
Fire and large fires have always been present in the social context, often with loss of human lives and material possessions. The regulations of the Fire Department seek to remedy this problem, however the conditions of accessibility and mobility of urban roads have made it difficult to provide the emergency public service in a fire situation. It also contributes to this scenario, the fragmented process of Brazilian urbanization, where families started occupying areas that were not suitable for human housing. The concepts of urban mobility are largely treated in the sense of restricting the movement of cars and encouraging the movement of people, without considering the issue of access of emergency vehicles. The objective of this research was to verify the geometric conditions of urban roads in three municipalities around Curitiba, which presented irregularities in width, minimum turning radius and minimum vertical jig of their tracks. For this verification, it was necessary to generalize the concepts of the urban roads of the municipalities, as a function of the Brazilian Traffic Code (BRASIL, 1997), as well as of the vehicles of the Fire Department according to the Manual of Geometric Project of Urban Crossings (BRASIL, 2010).
\end{abstract}

Keywords: Urbanization; Firefighters; Mobility.

Artigo recebido em 05/12/16 e Aceito em 09/01/17 


\section{INTRODUÇÃO}

Os últimos anos foram marcados pela crescente preocupação com a segurança contra incêndio e pânico em edificações, em especial pelo recente acontecimento na Boate Kiss, cidade de Santa Maria no Rio Grande do Sul, que vitimou 242 pessoas. A partir daí, uma mobilização nacional quanto à melhoria de suas legislações de segurança contra incêndio e pânico, em que o Estado do Paraná foi precursor neste processo, com a atualização de sua legislação antes mesmo deste incêndio que dizimou os frequentadores da referida boate. Dentre as inovações dessa nova legislação está a previsão de condições adequadas para o acesso das equipes de bombeiros nas edificações, e ainda, a mobilidade das viaturas em vias urbanas.

O processo de urbanização brasileira gerou uma concentração populacional nos centros urbanos, trazendo consigo um crescimento desordenado das cidades, visto que a população passou a ocupar desordenadamente áreas informais, muitas vezes inadequadas à habitação e sem a presença da infraestrutura básica para a sobrevivência humana.

$\mathrm{Na}$ segunda metade do século $\mathrm{XX}$, a política urbana brasileira foi orientada por legislação e programas federais de habitação, sendo que, de modo geral, a legislação municipal se restringia à delimitação de perímetros e aprovação de códigos de obras e posturas, o que dificultou a implantação de várias políticas municipais, pois havia uma tentativa de padronizar o desenvolvimento urbano, em desatenção a todas as particularidades locais e as enormes diferenças entre as cidades brasileiras. Associado a isto, por vezes, os municípios acabam por fornecer condições básicas de infraestrutura urbana, sem atentar a aspectos que afetam a segurança e o bem estar humano.

Com a aprovação da Lei Federal no 10.257 de 2001, denominada Estatuto da Cidade, passou a existir um conjunto de instrumentos urbanísticos e jurídicos, que possibilitaram o desenvolvimento de políticas urbanas por meio da aplicação de instrumentos de reforma urbana, voltados à promoção da inclusão social e territorial nas cidades brasileiras, considerando aspectos urbanos, sociais e políticos. 
Logo, surge a preocupação da União na garantia da prestação dos serviços públicos, por meio de uma infraestrutura urbana adequada, atendendo assim aos interesses e necessidades da população, podendo se inserir nesta condição o serviço público de emergência prestado pelos Corpos de Bombeiros em todo país.

Cabe aos municípios a política de desenvolvimento urbano, com o objetivo de ordenar o pleno desenvolvimento das funções sociais da cidade e garantir o bemestar de seus habitantes, no entanto a segurança pública é dever do Estado e por vezes demandado em áreas urbanas, com dificuldades de mobilidade e acessibilidade face às peculiaridades das vias urbanas.

Com isto, nos deparamos com um processo de urbanização todo fragmentado, com políticas urbanas distorcidas e desvinculadas entre os entes federativos, de outro às exigências normativas do Corpo de Bombeiros de Paraná (CBPR), no que tange a acessibilidade e mobilidade nas vias urbanas.

O objetivo desta pesquisa é verificar as condições geométricas de vias urbanas para o acesso do serviço público de emergência em situações de incêndio, nos três municípios com indicadores demográficos, sociais e econômicos mais altos, situados no Núcleo Urbano Central de Curitiba (NUC), entre os anos de 2011 a 2013.

\section{DESENVOLVIMENTO}

\subsection{Materiais e Métodos}

A tipologia adotada para este artigo é a de projetos sequenciais exploratórios, no qual, segundo Robson (2011), é caracterizado por uma fase inicial de coleta e análise de dados qualitativos seguidas de uma fase de coleta de dados e análises quantitativas. A prioridade é dada aos aspectos qualitativos do estudo.

Dentro do que uma estrutura múltipla de pesquisa possibilita, dois métodos foram utilizados: a pesquisa exploratória, por meio da busca de referenciais bibliográficos; e o estudo de caso, focado na verificação das condições geométricas de vias urbanas, em função da sua classificação e características.

Para a definição dos parâmetros deste artigo foi verificado os indicadores sociais, econômicos e demográficos dos municípios do NUC, sendo que os três 
municípios que apresentaram maior relevância na informação estatística, estão elencados na tabela 1 do Apêndice. A partir disto, foram avaliadas as exigências da legislação urbano-regional em função de sua categorização e hierarquização, e por consequência as prescrições geométricas de vias urbanas.

Conforme as definições apresentadas pelo Código de Trânsito Brasileiro (CTB) foi possível agrupar os conceitos das vias presentes na legislação urbanoregional e no Manual de Projeto Geométrico de Travessias Urbanas (MPGTU), buscando-se assim uma padronização das definições. Assim, as vias urbanas foram avaliadas com uma única definição, a constante no CTB (BRASIL, 1997).

O Conselho Nacional de Trânsito (CONTRAN) estabeleceu as dimensões máximas permitidas para os veículos que transitam na malha viária brasileira. Com base nisto surge o conceito de "Veículo de Projeto", em que as vias urbanas deveriam atender a condição de deslocamento destes. Assim os veículos de emergência do CBPR foram categorizados em função de suas dimensões e características de operação, adotando-se o conceito de "Veículos Tipo", com a mesma classificação adotada pelo MPGTU (BRASIL, 2010). A tabela 2 do Apêndice apresenta as dimensões médias destes tipos de viaturas e suas correlações com os veículos tipo do MPGTU (BRASIL, 2010).

Desta forma, os veículos do CBPR foram considerados "Veículos Tipo" e verificada a sua condição de mobilidade nas vias urbanas. A partir da revisão bibliográfica foram definidas as variáveis (largura da via, gabarito vertical mínimo e raio mínimo de giro na via) a serem aferidas e analisadas em campo, a fim de verificar as condições geométricas para acesso do serviço público de emergência na área de estudo.

\subsection{Mobilidade urbana}

O acelerado processo de urbanização no Brasil, em que a população deixou as áreas rurais e se deslocou às cidades, trouxe prejuízos a estas, visto que não havia preparação para tal crescimento. Dessa forma, as ações dos entes públicos sobre as cidades passaram a ser bem mais corretivas do que preventivas, não 
alcançando resoluções aos problemas estruturais que vinham se multiplicando, juntamente com o crescimento avantajado e anômalo das cidades.

A mobilidade urbana está relacionada com a facilidade de deslocamentos das pessoas e bens no espaço urbano. De acordo com a Cartilha do Ministério das Cidades (BRASIL, 2008), os deslocamentos são feitos através de veículos, vias e toda a infraestrutura (vias, calçadas) que possibilitam esse ir e vir cotidiano. Isso significa que a mobilidade urbana é mais do que o que chamamos de transporte urbano, ou seja, mais do que o conjunto de serviços e meios de deslocamento de pessoas e bens, sendo o resultado da interação entre os deslocamentos de pessoas e bens com a cidade.

Por isso, é forçoso entender a mobilidade como condição sob a qual grupos ou indivíduos interagem com os espaços, configurando-a tanto como uma das entradas possíveis para a apreensão do fenômeno urbano, como também uma ferramenta de empoderamento e superação das desigualdades.

Denota-se que os conceitos de mobilidade urbana são voltados ao deslocamento dos habitantes de determinada região, ao trabalho, ao estudo, o modal utilizado e a energia consumida, deixando de associar de alguma forma as condições de acesso ao espaço urbano das cidades.

Os conceitos que buscam novas tecnologias são conduzidos por esta realidade, em que o ser humano se desloca em busca de sua subsistência. Assim, Moller (2006) defende que a cidade deve ser redesenhada à escala do pedestre, ou seja, fomentar a micro mobilidade (distâncias curtas a pé ou em bicicleta) e minimizar a macro mobilidade (grandes distâncias percorridas em automóveis).

Surge assim uma total despreocupação com a utilização dos espaços urbanos no que tange a prestação de alguns serviços públicos, os quais dependem e se fazem por vias urbanas nas cidades, visto que é analisada apenas a vertente do cidadão e de sua mobilidade, em que o objetivo é construir espaços diversificados que encorajam a convivência e priorizam o transporte não motorizado. Mascaro (2005) argumenta que não há outra maneira de fazê-lo senão restringindo ao máximo os deslocamentos motorizados e isto será possível apenas com a redução do espaço destinado aos automóveis. 
Revista Científica do Corpo de Bombeiros Militar de Pernambuco

Seção 1 - Artigos Técnico Científicos

Artigo publicado no Vol.03 №06 - Edição de JAN a JUN 2017 - ISSN 2359-4829

Versão on-line disponível em: $\underline{\text { http://www.revistaflammae.com }}$

A figura 1 representa bem essa visão sistêmica do processo, sem que uma análise mais global seja realizada, em que o desenho das vias e intersecções em escala local deve ser feitos com o propósito de dificultar a circulação dos automóveis, minimizando sua velocidade com o redimensionamento do leito carroçável, com traçados irregulares, inferindo assim no deslocamento de viaturas de emergência, como por exemplo, as do Corpo de Bombeiros.

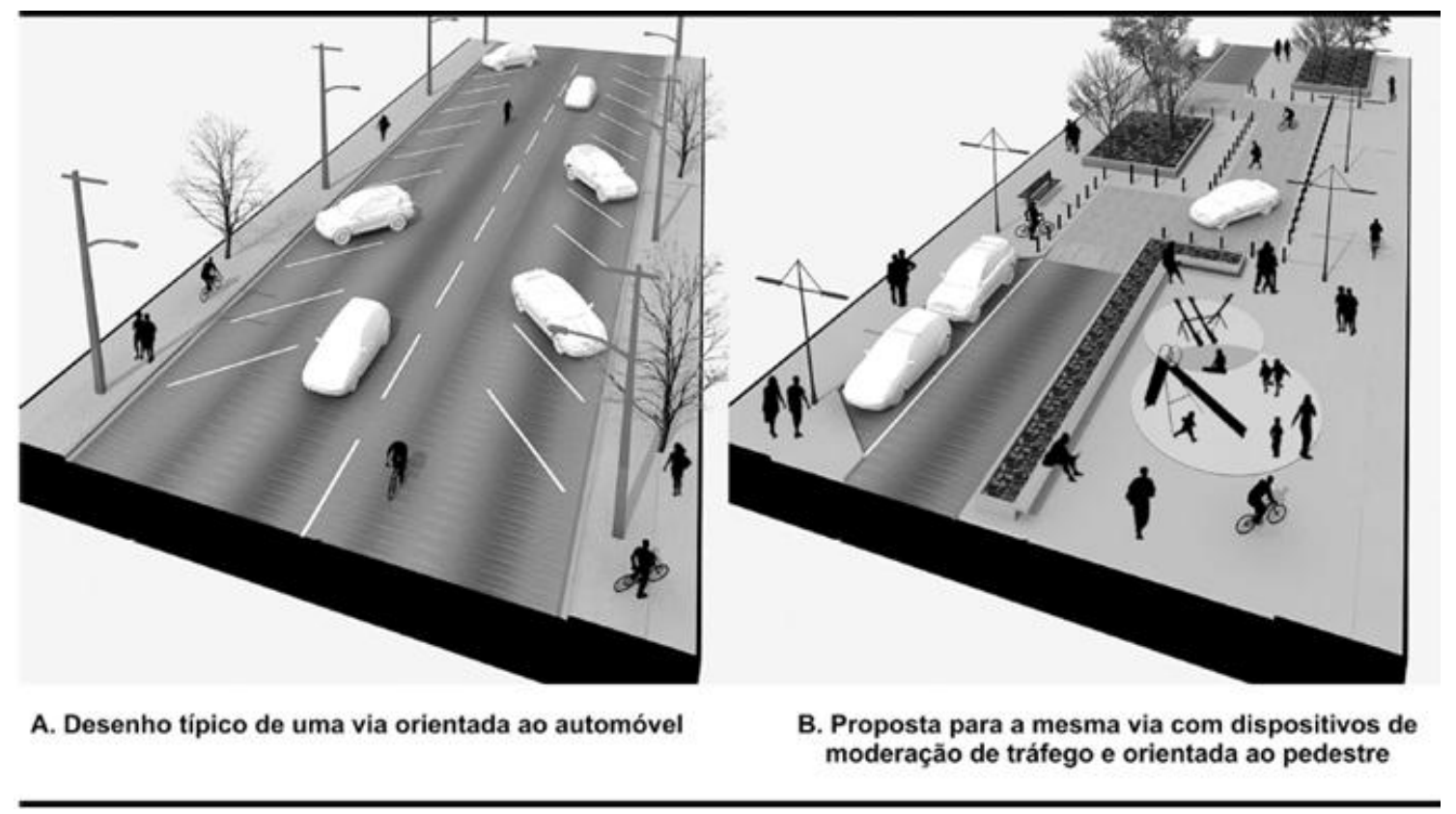

Figura 1 - Proposta de uma via urbana com circulação compartilhada Fonte: Barczak (2009)

Tradicionalmente, a acessibilidade física é vista como a facilidade de atingir os destinos desejados, como a medida direta e positiva dos efeitos de um sistema de transporte. $\mathrm{Na}$ forma mais simples, a acessibilidade pode ser medida pelo número, natureza e maneira que os destinos podem ser alcançados. Vasconcellos (2001) cita que uma das medidas básicas da acessibilidade é dada pela disponibilidade de espaços viários ou de sistemas adequados à circulação.

Assim, no contexto desta pesquisa, a mobilidade é aferida pela condição de acessibilidade dos veículos de atendimento emergencial em situações de incêndio. 


\subsection{CSCIP do Corpo de Bombeiros do Paraná}

Por meio do Código de Segurança Contra Incêndio e Pânico (CSCIP) $)^{2}$, o CBPR adota medidas de segurança para prevenir a ocorrência de incêndios, visando à proteção da vida dos ocupantes das edificações, dificultar a propagação do incêndio, reduzindo danos ao meio ambiente e ao patrimônio, e ainda proporcionar meios de controle e extinção do incêndio, sendo necessário regrar as condições de acesso para as operações do Corpo de Bombeiros.

Dentro da temática apresentada por esta pesquisa, a Norma de Procedimento Técnico (NPT) 05 do CSCIP do fixa as condições mínimas exigíveis para o deslocamento de viaturas de bombeiros nas vias públicas, dentre as quais podemos citar as exigências para as vias urbanas, as passagens subterrâneas e viadutos. A NPT 05 (BOMBEIROS, 2011) estabelece que a via urbana deve possuir largura mínima de 6,0 m e altura livre mínima de 4,50 m.

Neste sentido, Almeida (2008) diz que deve ser garantida a acessibilidade dos veículos de socorro dos bombeiros aos meios de abastecimento de água (hidrantes exteriores, colunas secas), reservando o espaço suficiente para garantir a manobra.

\subsection{Manual de Projeto Geométrico de Travessias Urbanas (MPGTU)}

O Departamento Nacional de Infraestrutura de Transportes (DNIT), submetido ao regime autárquico, vinculado ao Ministério dos Transportes, por meio do Manual de Projeto Geométrico de Travessias Urbanas do DNIT (BRASIL, 2010), estabelece as diretrizes técnicas para as vias urbanas.

O MPGTU (BRASIL, 2010) apresenta os critérios que condicionam o estabelecimento e adoção das características técnicas básicas do projeto geométrico de vias urbanas, tais como a largura das vias e da faixa de rolamento, dos passeios e o gabarito vertical mínimo.

\footnotetext{
${ }^{2}$ Instituído no âmbito do Corpo de Bombeiros da PMPR, por meio da Portaria do Comando do Corpo de Bombeiros no 002/11.
} 
Revista Científica do Corpo de Bombeiros Militar de Pernambuco

Seção 1 - Artigos Técnico Científicos

Artigo publicado no Vol.03 №06 - Edição de JAN a JUN 2017 - ISSN 2359-4829

Versão on-line disponível em: $\underline{\text { http://www.revistaflammae.com }}$

Nos termos do MPGTU (BRASIL, 2010) a largura básica recomendada para cada faixa de rolamento para vias expressas é de 3,60 m. Em áreas urbanas onde travessias de pedestres, faixas de domínio, ou desenvolvimento local se tornam fatores efetivos de controle, o uso de faixas de 3,30 m é aceitável. Faixas de 3,00 m de largura são apropriadas para rodovias de baixa velocidade, e faixas de 2,70 m para rodovias de baixo volume em áreas rurais e residenciais.

Gabarito vertical é altura livre mínima permitida em uma via, ou seja, é a distância da superfície da pista a um obstáculo superior mais próximo (BRASIL, DNIT, 2010). O MPGTU (BRASIL, 2010) cita que para as vias expressas, o maior gabarito vertical em uso no País, adotado nas rodovias e em algumas das principais vias urbanas (anéis rodoviários e vias expressas), é de 5,50 m.

Outra característica importante a ser considerada nas vias é o raio mínimo de giro. Segundo o MPGTU (BRASIL, 2010) é o raio da trajetória descrita pela roda externa dianteira, quando o veículo executa seu giro mais fechado possível a baixa velocidade, em geral nunca superior a $15 \mathrm{~km} / \mathrm{h}$.

O MPGTU (BRASIL, 2010) adota nove classes para os veículos de projeto, nos termos da figura 2, sendo que somente os veículos VP, $\mathrm{CO}, \mathrm{O}$ e $\mathrm{CA}$, apresentam correlação com este estudo, nos termos da tabela 2 do Apêndice.

Figura 2 - Principais dimensões básicas dos veículos de projeto(m)

\begin{tabular}{|c|c|c|c|c|c|c|c|c|c|}
\hline \multirow[b]{2}{*}{$\begin{array}{l}\text { Caracte- } \\
\text { rísticas }\end{array}$} & \multicolumn{9}{|c|}{ Designaçâo do Veículo } \\
\hline & $\begin{array}{l}\text { Veiculo } \\
\text { leve } \\
\text { (VP) }\end{array}$ & $\begin{array}{c}\text { Cam./ } \\
\text { Ônibus } \\
\text { conv. } \\
\text { (CO) }\end{array}$ & $\begin{array}{c}\text { Onibus } \\
\text { urbano } \\
\text { longo } \\
\text { (O) }\end{array}$ & $\begin{array}{c}\text { Ônibus } \\
\text { rodoviá } \\
\text { rioo } \\
\text { (OR) }\end{array}$ & $\begin{array}{c}\text { Carreta } \\
\text { (CA) }\end{array}$ & $\begin{array}{c}\text { Bitrem } \\
\text { de } 7 \\
\text { eixos } \\
\text { (BT7) }\end{array}$ & $\begin{array}{l}\text { Cego- } \\
\text { nheiro } \\
\text { (CG) }\end{array}$ & $\begin{array}{c}\text { Bitrem } \\
\text { de } 9 \\
\text { eixos } \\
\text { (BT9) }\end{array}$ & $\begin{array}{c}\text { Bitrem } \\
\text { longo/ } \\
\text { Rodotr. } \\
\text { (BTL) }\end{array}$ \\
\hline Largura total & 2,1 & 2,6 & 2,6 & 2,6 & 2,6 & 2,6 & 2,6 & 2,6 & 2,6 \\
\hline $\begin{array}{c}\text { Comprimento } \\
\text { total }\end{array}$ & 5,8 & 9,1 & 12,2 & 14,0 & 18,6 & 19,8 & 22,4 & 25,0 & 30,0 \\
\hline $\begin{array}{c}\text { Raio min. } \\
\text { da roda externa } \\
\text { dianteira }\end{array}$ & 7,3 & 12,8 & 12,8 & 13,8 & 13,7 & 13,7 & 13,7 & 14,8 & 16,6 \\
\hline $\begin{array}{l}\text { Raio de giro do } \\
\text { eixo dianteiro } \\
\text { (RED) }\end{array}$ & 6,4 & 11,5 & 11,5 & 12,5 & 12,5 & 12,5 & 12,5 & 13,6 & 15,4 \\
\hline $\begin{array}{c}\text { Raio min. da } \\
\text { roda interna } \\
\text { traseira }\end{array}$ & 4,7 & 8,7 & 7,1 & 7,7 & 6,1 & 6,8 & 1,6 & 4,5 & 3,9 \\
\hline
\end{tabular}

Fonte: MPGTU (BRASIL, 2010), adaptado pelo autor (2015) 
Para as características apresentadas, Lee (2008) afirma que os parâmetros de projeto geométrico estabelecidos pelas normas do DNIT consideram o caso geral de atendimento com os veículos tipo $\mathrm{CO}$, conforme demonstrado na figura 3 .

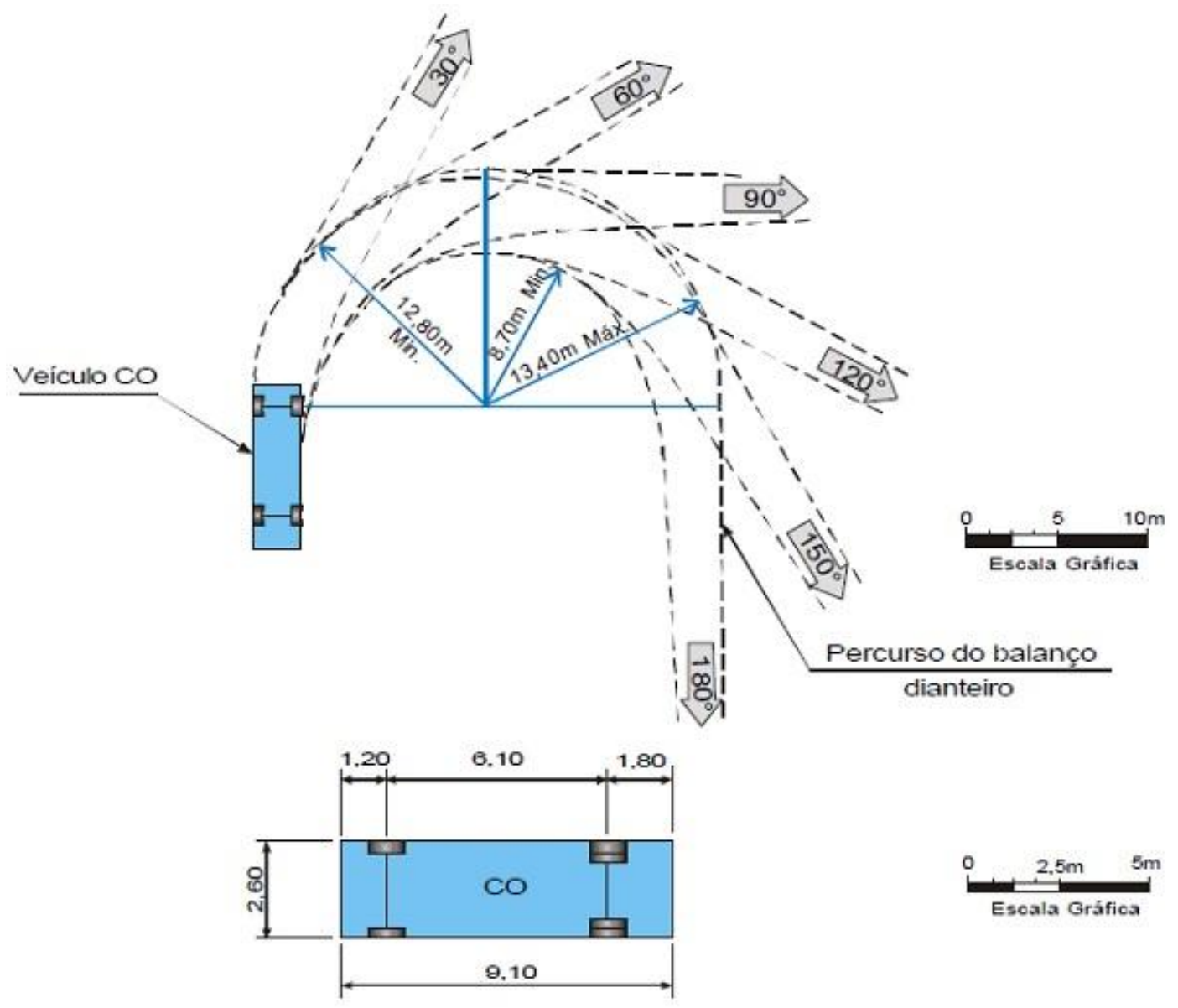

Figura 3 - Dimensões e gabaritos de giro para veículo tipo $\mathrm{CO}$ Fonte: MPGTU (BRASIL, 2010), adaptado pelo autor (2015)

\section{RESULTADOS}

Com base nos dados estatísticos apresentados e hierarquizados dos três municípios do NUC, partiu-se para o estudo de campo das condições de mobilidade e acessibilidade do serviço público de emergência, em função das prescrições da legislação urbano-regional e do MPGTU (BRASIL, 2010).

Um local de estudo compreende uma zona residencial do município de São José dos Pinhais, com acesso por via arterial (rua Silvio Pinto Ribeiro) e desta para 


\section{Revista FLAMMAE}

Revista Científica do Corpo de Bombeiros Militar de Pernambuco

Seção 1 - Artigos Técnico Científicos

Artigo publicado no Vol.03 №06 - Edição de JAN a JUN 2017 - ISSN 2359-4829

Versão on-line disponível em: http://www.revistaflammae.com

uma via local (rua João Palma Moreira), a qual dá acesso às outras três vias locais (rua 79 , rua 78 , rua 71 e rua 83 ), conforme demonstrado na figura 4 .

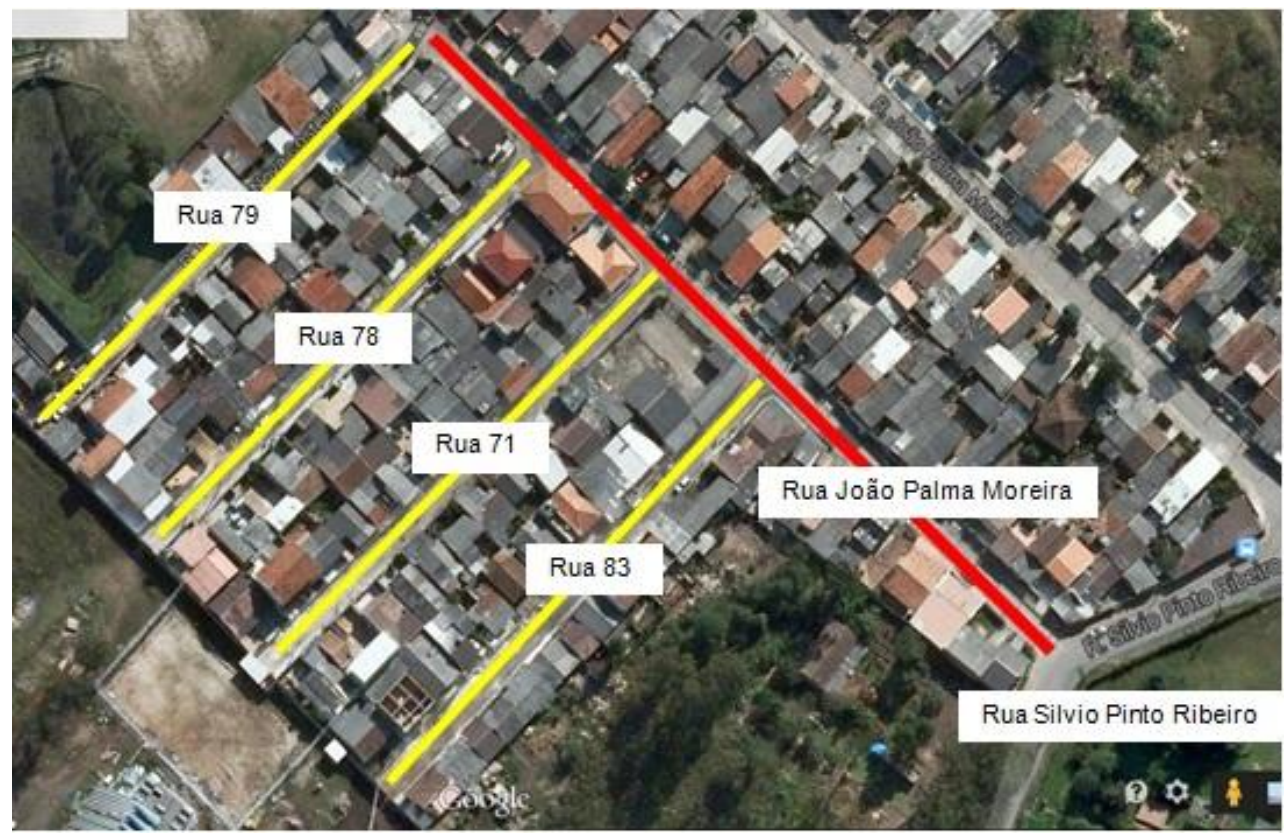

Figura 4 - Município de São José dos Pinhais, zona residencial de estudo Fonte: Fernandes (2015)

As ruas $79,78,71$ e 83 estão representadas na figura 5 , assim como as suas larguras e de seus passeios. 


\section{Revista FLAMMAE}

Revista Científica do Corpo de Bombeiros Militar de Pernambuco

Seção 1 - Artigos Técnico Científicos

Artigo publicado no Vol.03 №06 - Edição de JAN a JUN 2017 - ISSN 2359-4829

Versão on-line disponível em: http://www.revistaflammae.com

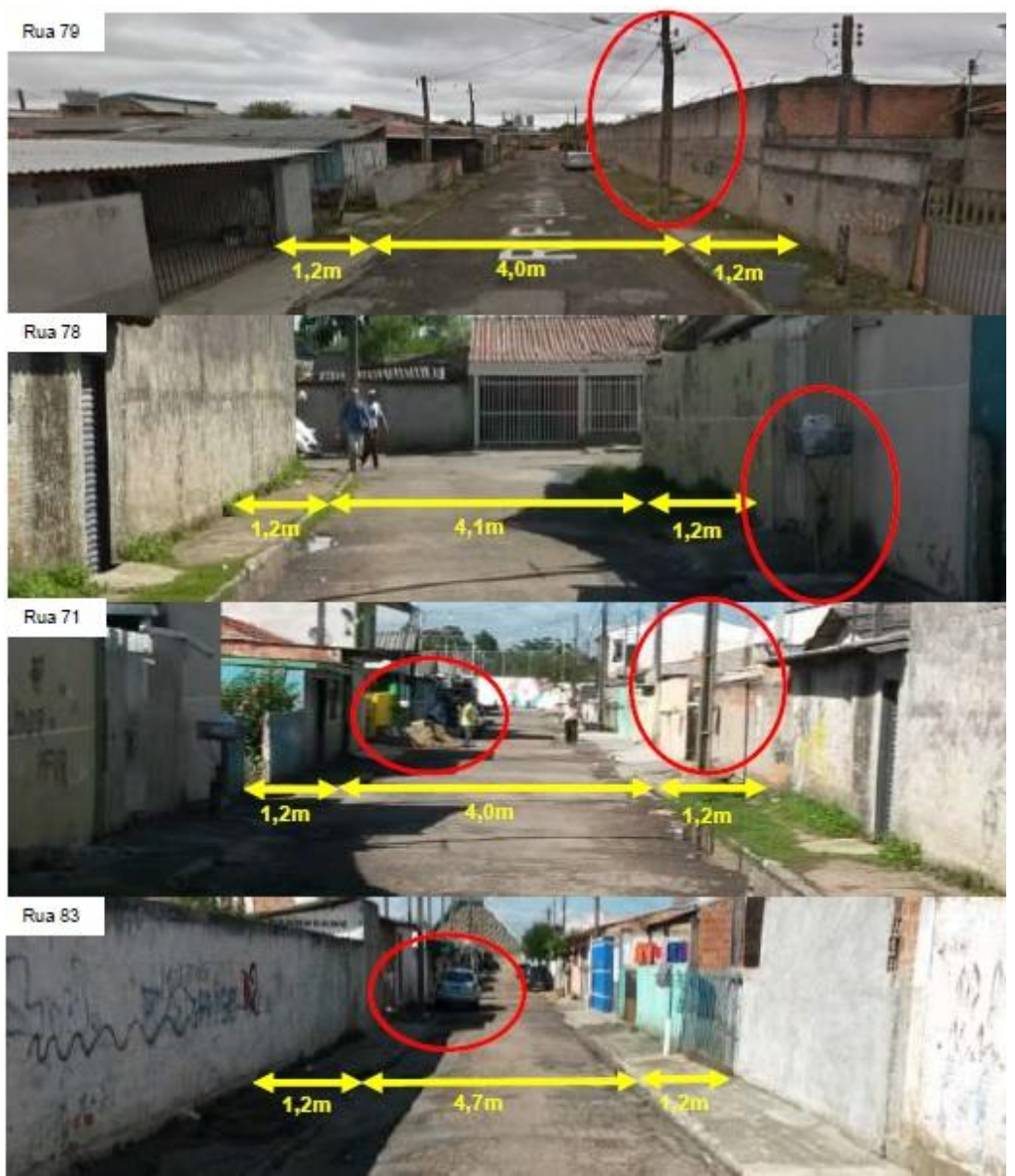

Figura 5 - Município de São José dos Pinhais, ruas 79, 78, 71 e 83 Fonte: Fernandes (2015)

A normativa do CBPR quanto a largura mínima $(6,00 \mathrm{~m})$ da via não é atendida, em especial pela condição dos postes de iluminação pública. Nestes casos, em função do raio de giro necessário para um veículo tipo $\mathrm{CO}$, o acesso das viaturas do CBPR não seria possível, pois a condição do raio mínimo de giro para a roda externa dianteira de $12,80 \mathrm{~m}$ e de $8,70 \mathrm{~m}$ para a roda interna traseira não são atendidos, conforme figura 6. 


\section{Revista FLAMMAE}

Revista Científica do Corpo de Bombeiros Militar de Pernambuco

Seção 1 - Artigos Técnico Científicos

Artigo publicado no Vol.03 №06 - Edição de JAN a JUN 2017 - ISSN 2359-4829

Versão on-line disponível em: http://www.revistaflammae.com

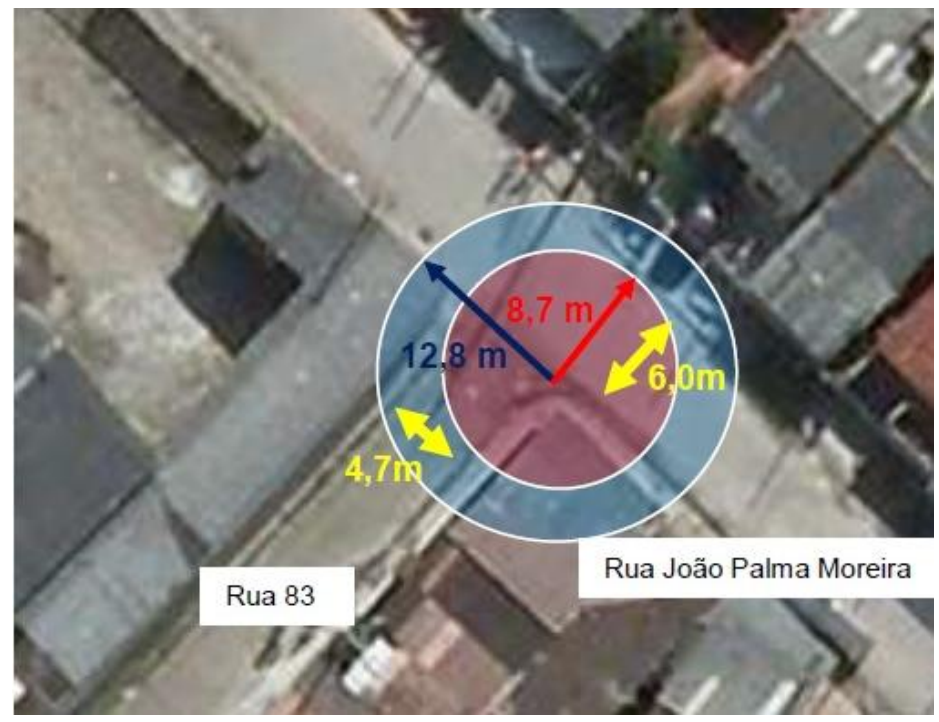

Figura 6 - Município de São José dos Pinhais, simulação do raio de giro da rua João Palma Moreira para a rua 83

Fonte: Fernandes (2015)

Para o estudo de uma rotatória foi aferida a confluência das ruas Bertolina de Oliveira com Antonio Batista de Siqueira, no município de Almirante Tamandaré, conforme figura 7.

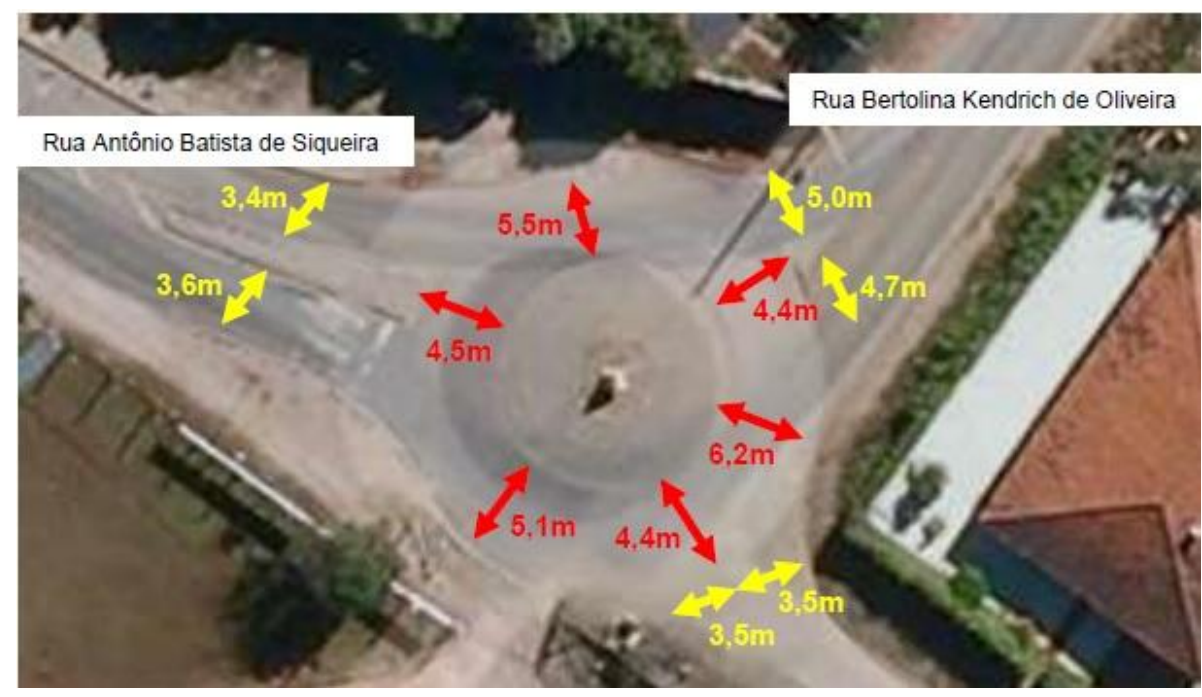

Figura 7 - Município de Almirante Tamandaré, rótula da rua Antônio Batista de Siqueira com a rua Bertolina Kendrich de Oliveira

Fonte: Fernandes (2015)

Da análise da rótula, se observa que o trecho circular da rótula não atende a especificação da NPT 06 (BOMBEIROS, 2011), por não possuir 6,00 m de largura. Em função disto e conforme as prescrições do MPGTU (BRASIL, 2010), o raio de 


\section{Revista FLAMMAE}

Revista Científica do Corpo de Bombeiros Militar de Pernambuco

Seção 1 - Artigos Técnico Científicos

Artigo publicado no Vol.03 №06 - Edição de JAN a JUN 2017 - ISSN 2359-4829

Versão on-line disponível em: http://www.revistaflammae.com

giro de um veículo tipo CO também fica prejudicado, por não se atingir as medidas exigíveis, conforme figura 8.

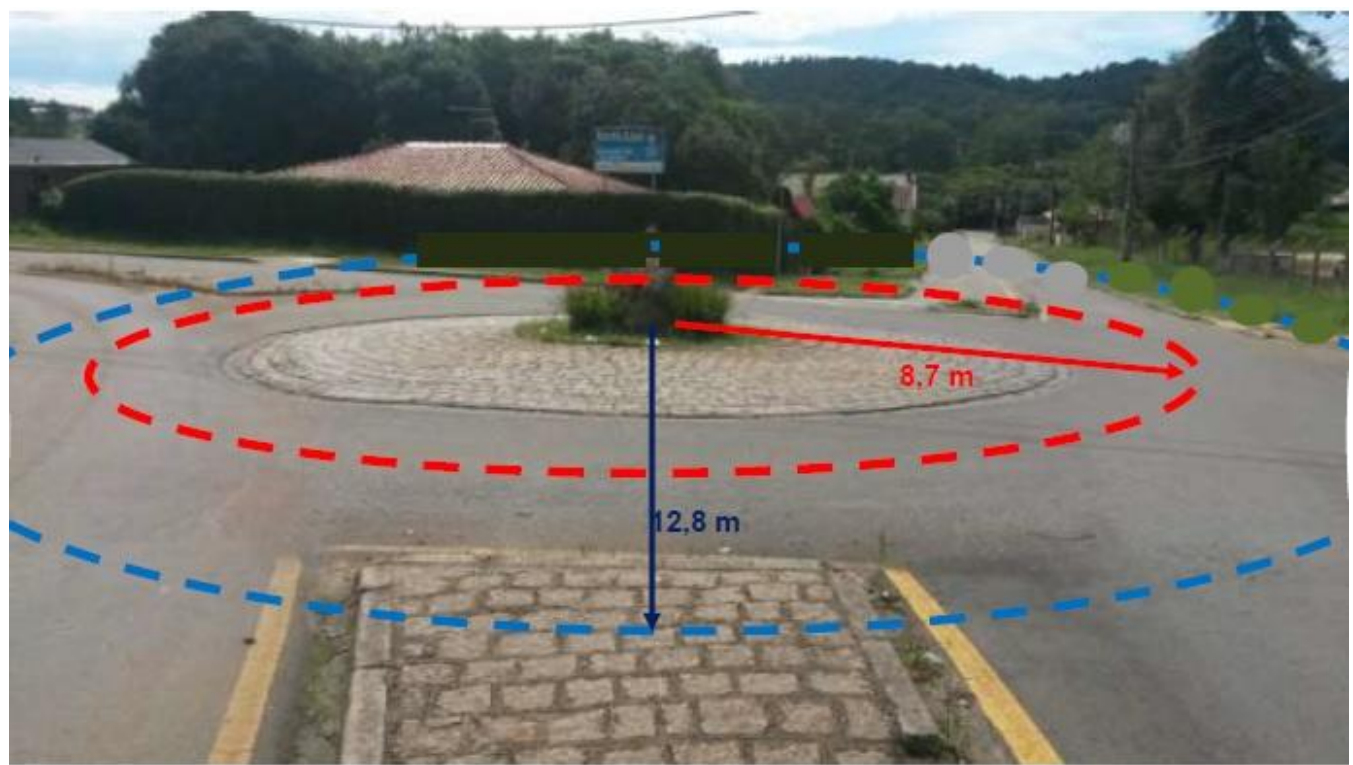

Figura 8 - Município de Almirante Tamandaré, traçado do raio de giro na rótula da rua Antônio Batista de Siqueira com a rua Bertolina Kendrich de Oliveira Fonte: Fernandes (2015)

Para o estudo do gabarito vertical mínimo, foram aferidas duas situações, uma em São José dos Pinhais e outra no município de Colombo. A figura 9 apresenta a trincheira da Avenida das Torres com Avenida Rui Barbosa.

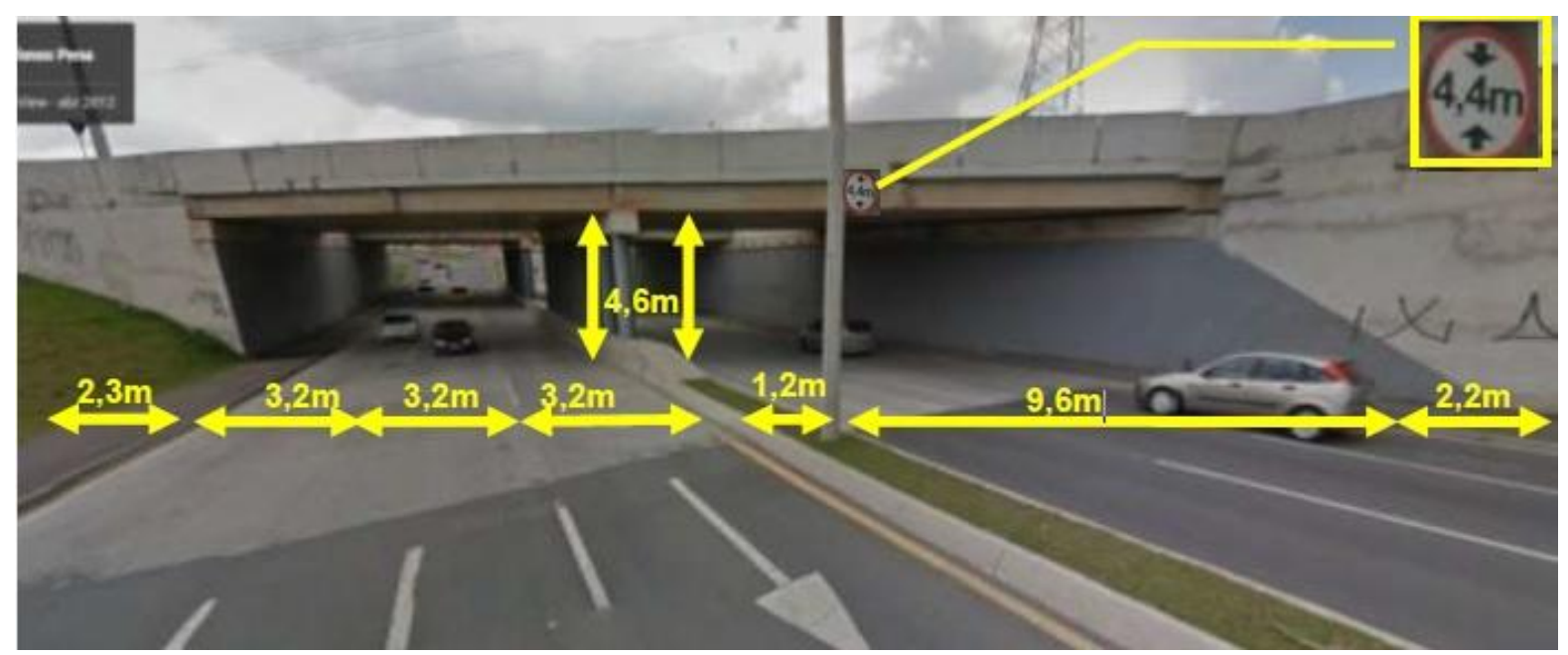

Figura 9 - Município de São José dos Pinhais, trincheira Av. das Torres com Av. Rui Barbosa

Fonte: Fernandes (2015) 
Revista Científica do Corpo de Bombeiros Militar de Pernambuco

Seção 1 - Artigos Técnico Científicos

Artigo publicado no Vol.03 №06 - Edição de JAN a JUN 2017 - ISSN 2359-4829

Versão on-line disponível em: $\underline{\text { http://www.revistaflammae.com }}$

Detalhe importante a ser citado é o gabarito vertical mínimo da via arterial, visto que o MPGTU (BRASIL, 2010) recomenda para esta situação o mínimo de 5,50 $\mathrm{m}$, sendo que no local foi aferida a altura de 4,60 m com limitação em 4,40 m, conforme se observa na figura 9. Para esta mesma condição a NPT 05 do CBPR estabelece o mínimo de 4,50 m.

No município de Colombo a trincheira existente na rua Dezenove de Novembro com a BR 476, também foi estudada, e conforme demonstrado na figura 10, a largura da via é de $3,40 \mathrm{~m}$ e altura limitada em 4,00 m.

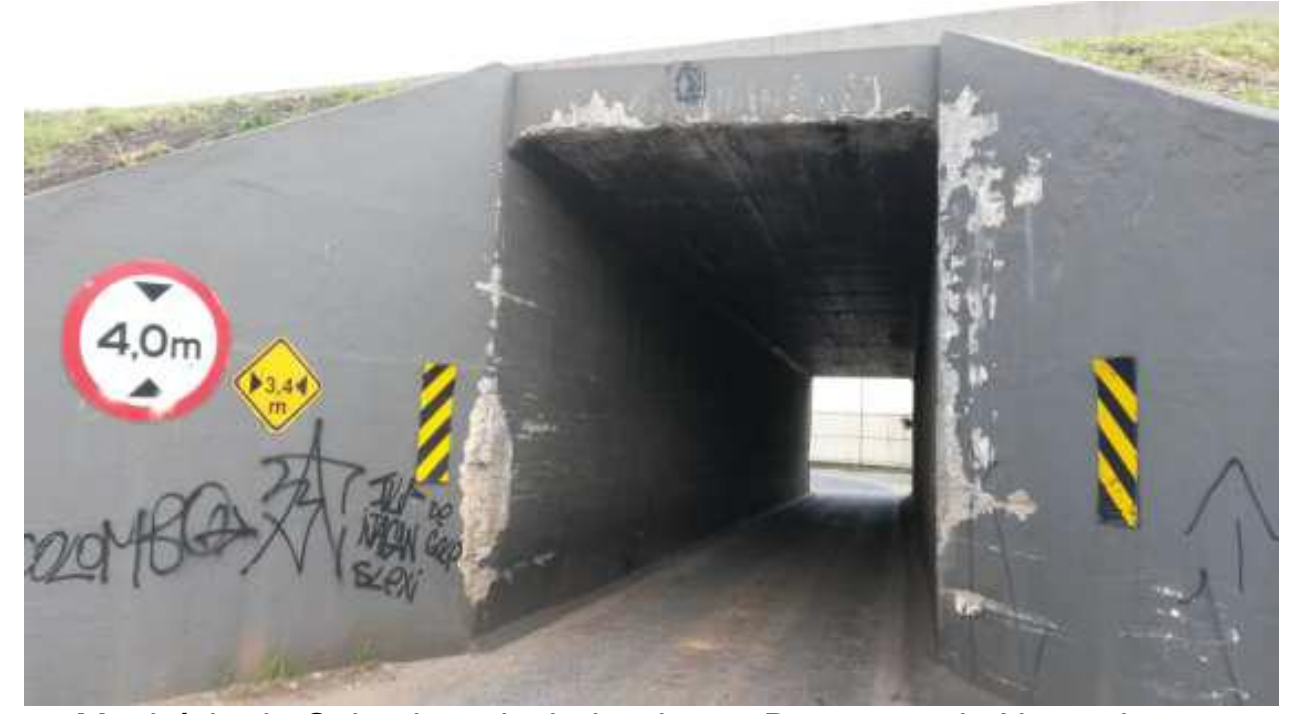

Figura 10 - Município de Colombo, trincheira da rua Dezenove de Novembro com a BR 476 Fonte: Fernandes (2015)

Ao se considerar as condições geométricas das vias urbanas estudadas, se faz entender que a participação do Corpo de Bombeiros neste processo é justamente pela mobilidade nas vias e acessibilidade às edificações. A mobilidade se dá por meio do deslocamento em vias urbanas, as quais devem estar devidamente dimensionadas, e a acessibilidade, por sua vez, é o acesso propriamente dito ao local/edificação em que se prestará o socorro público. A falta de ambos acarreta transtornos e dificuldades à prestação do serviço público de emergência.

Num conceito operacional mais amplo, mobilidade e acessibilidade devem ser entendidas como o trajeto desde o posto de bombeiros até o local da ocorrência. Decorre disso as exigências urbanísticas e de acesso de viaturas às edificações, 
prescritas no CSICP, sobretudo na NPT 05, com respaldo técnico do MPGTU (BRASIL, 2010).

Assim, a malha viária urbana deve atender às necessidades do Corpo de Bombeiros e neste sentido Mascaro (2005) afirma que na maioria das vezes, quando se projeta o arruamento de uma zona urbana, não se leva em consideração as funções reais a que se destinam essas ruas.

\section{CONCLUSÕES}

O objetivo desta pesquisa foi verificar as condições geométricas de vias urbanas para o acesso do serviço público de emergência em situações de incêndio, no entorno de Curitiba.

De uma forma geral, podemos concluir que a falta de infraestrutura é verificada nas condições geométricas da malha viária urbana estudada, em que há severas condicionantes restritivas à prestação do serviço público de emergência em situações de incêndio, por meio do acesso de viaturas do Corpo de Bombeiros.

O método de análise dos dados se mostrou adequado aos objetivos desta pesquisa, pois foi possível quantificar e mensurar qualitativamente as condições geométricas das vias, as quais não atendem às recomendações normativas. Assim ações de alargamento das vias e correção do raio mínimo de giro em rótulas, redimensionamento de passeios, pavimentação, relocação de iluminação pública e intervenção no domínio das propriedades, podem ser indicadas aos municípios como forma de regularização. Da mesma forma, alterações no passeio, pavimentação e rebaixamento do greide da via podem ser indicados como forma de adequação do gabarito vertical mínimo das vias urbanas.

Essas ações de regularização devem ser entendidas com metas desejáveis; reconhece-se que, em muitos casos, as condições existentes não permitirão sua implantação sem onerar por demais o custo de um programa de melhorias, ou mesmo, interferir excessivamente nas estruturas urbanas existentes e mesmo no fluxo de tráfego durante a regularização/construção. Da mesma forma, a necessidade de adquirir faixa de domínio em áreas muito desenvolvidas, pode ser 
onerosa. Alternativamente, pode-se adotar características técnicas inferiores às que seriam empregadas se as faixas de domínio existentes fossem suficientes ou pudessem ser ampliadas a baixo custo.

Neste contexto, é importante destacar a necessidade de intervenção do poder público nas ações de regularização, o que poderia envolver as questões legais de domínio das vias, por meio de legislações específicas de regularização, desapropriação e outras ações.

Sendo assim, há necessidade de se estruturar um conjunto de conceitos, métodos, instruções e critérios técnicos que possibilitem a implantação de vias urbanas de alto padrão, atendendo também às peculiaridades urbanas.

Preventivamente é possível propor políticas públicas, por meio de ações que visem à melhoria dos sistemas viários municipais, atentando para a temática do acesso do serviço público de emergência em situações de incêndio, com a realização e aprofundamento de estudos que sirvam de subsídio para a estruturação viária e, ainda, o estabelecimento de diretrizes de arruamento que contemplem áreas ainda não urbanizadas.

\section{REFERÊNCIAS}

ALMEIDA, J. E. Organização e Gestão da Segurança em Incêndios Urbanos. Departamento de Engenharia Civil Faculdade de Ciências e Tecnologia da Universidade de Coimbra. 2008

ALMIRANTE TAMANDARÉ. Lei municipal № 1204, de 03 de outubro de 2006. Sistema Viário do Município. Curitiba: Imprensa Oficial, 2006.

BARCZACK, Rafael Sindelar. Estratégias de mitigação e compensação das emissões de $\mathrm{CO} 2$ na mobilidade urbana: uma análise da produção científica internacional. Curitiba: Pontifícia Universidade Católica do Paraná. 2009. 288p. (Dissertação, mestrado em Gestão Urbana). 
CORPO DE BOMBEIROS DO PARANÁ. Código de Segurança Contra Incêndio e Pânico. Disponível em: <http://www.bombeiros.pr.gov.br>. Acesso em: 07 set.2015.

BRASIL. Ministério das Cidades. Cartilha do Ministério das Cidades. URBS, 2008.

BRASIL. Ministério das Cidades. Conselho Nacional de Trânsito. Resolução no 210 de 13 de novembro de 2006. Diário Oficial da União, Brasília, DF.

BRASIL. Departamento Nacional de Infraestrutura de Transportes. Diretoria Executiva. Instituto de Pesquisas Rodoviárias. Manual de projeto geométrico de travessias urbanas. - Rio de Janeiro, 2010.

COLOMBO. Lei municipal no 875 , de 16 de fevereiro de 2004. Plano Diretor Municipal. Curitiba: Imprensa Oficial, 2004.

COLOMBO. Lei municipal ํo $\mathbf{8 7 8}$, de 16 de fevereiro de 2004. Parcelamento do Solo. Curitiba: Imprensa Oficial, 2004.

FERNANDES, Ivan Ricardo. Condições geométricas de vias urbanas para o acesso do serviço público de emergência em situações de incêndio: estudo de caso em cinco municípios do entorno de Curitiba (Paraná) a partir do Estatuto da Cidade (2001). Curitiba: Universidade Federal do Paraná. 2015. 188 p. (Dissertação, mestrado em Construção Civil: Ambiente Construído).

LEE, Shu Han. Introdução ao projeto geométrico de rodovias. 3.ed. Florianópolis: Ed. Da UFSC, 2008.

MASCARO, J. L. Loteamentos urbanos. Porto Alegre: J. Mascaro, 2005. 
MOLLER, R. Transporte urbano y desarrollo sostenible en América Latina: El ejemplo de Santiago de Cali, Colombia. 1. ed. Cali: Programa Editorial Universidad del Valle, 2006.

ROBSON, C. Real world research: a resource for social scientists and practitionerresearchers. 3 ed. Malden: Blackwell Publishers, 2011.

SÃO JOSÉ DOS PINHAIS. Lei complementar oㅡ 16, de 11 de novembro de 2005. Sistema Viário do Município. Curitiba: Imprensa Oficial, 2005. 
Revista Científica do Corpo de Bombeiros Militar de Pernambuco

Seção 1 - Artigos Técnico Científicos

Artigo publicado no Vol.03 №06 - Edição de JAN a JUN 2017 - ISSN 2359-4829

Versão on-line disponível em: http://www.revistaflammae.com

\section{APÊNDICE}

Tabela 1 - Hierarquização dos dados estatísticos dos municípios do NUC

\begin{tabular}{|c|c|c|c|c|c|c|c|c|c|}
\hline & $\begin{array}{l}\bar{\pi} \\
\frac{0}{\circ} \\
\dot{0} \\
\dot{0}\end{array}$ & 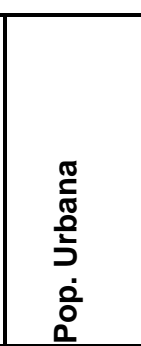 & 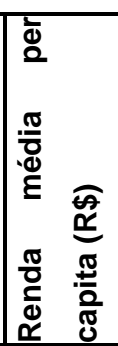 & 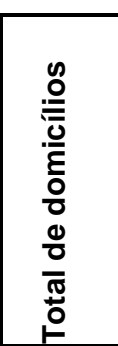 & 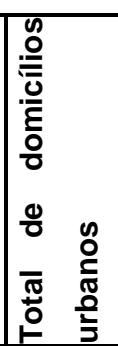 & 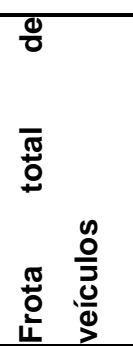 & 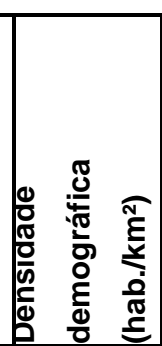 & 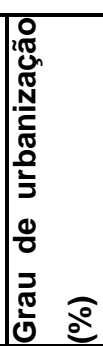 & 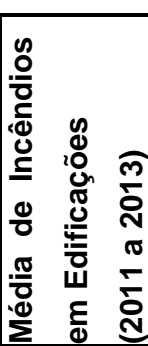 \\
\hline $\begin{array}{l}\text { Almirante } \\
\text { Tamandaré }\end{array}$ & 103.204 & 98.892 & 629,58 & 32.600 & 31.118 & 41.144 & 576,91 & 95,82 & 54,33 \\
\hline Colombo & 212.967 & 203.203 & 667,21 & 68.363 & 65.024 & 100.255 & $1.148,71$ & 95,42 & 82,00 \\
\hline $\begin{array}{l}\text { São José dos } \\
\text { Pinhais }\end{array}$ & 264.210 & 236.895 & 832,85 & 89.770 & 79.549 & 153.175 & 304,77 & 89,66 & 119,33 \\
\hline
\end{tabular}

Fonte: Fernandes (2015)

Tabela 2 - Especificação das dimensões das viaturas do CBPR em função dos veículos tipo do MPGTU (BRASIL, 2010)

\begin{tabular}{l|l|l|l|l|l|l|l}
\hline VTR/Dimensão & $\begin{array}{l}\text { No de } \\
\text { Eixos }\end{array}$ & $\begin{array}{l}\text { Comprimento } \\
(\mathbf{m})\end{array}$ & $\begin{array}{l}\text { Largura } \\
(\mathbf{m})\end{array}$ & $\begin{array}{l}\text { Altura } \\
(\mathbf{m})\end{array}$ & $\begin{array}{l}\text { Veículo } \\
\text { Tipo }\end{array}$ & $\begin{array}{l}\text { Comprimento } \\
(\mathbf{m})\end{array}$ & $\begin{array}{l}\text { Largura } \\
(\mathbf{m})\end{array}$ \\
\hline AA & 02 & 5,80 & 2,40 & 2,75 & VP & 5,80 & 2,10 \\
\hline ABT/ ABTR & 02 & 8,55 & 3,00 & 3,15 & CO & 9,10 & 2,60 \\
\hline AEM & 03 & 12,15 & 2,45 & 3,70 & O & 12,20 & 2,60 \\
\hline CT & 05 & 14,10 & 2,45 & 3,30 & CA & 18,60 & 2,60 \\
\hline
\end{tabular}

Fonte: Fernandes (2015) 